\title{
PELAKSANAAN INFORMATION PROFESSIONAL (IP) DALAM BIDANG ILMU INFORMASI, PERPUSTAKAAN DAN ARSIP
}

\author{
Moh. Very Setiawan ${ }^{*}$
}

\begin{abstract}
The amount of information often makes us confused to choose information. We cannot judge whether this is the right information or not. On this basis the existence of an Information Professional (IP) in an institution is important. This study aims to provide an overview of the IP and what they can do in the field of library science, information and archives. In this article the authors review some literature related to the implementation of IP, institutions engaged in IP services and institutions that provide IP training. This study explains that: 1. IP jobs can come from a variety of educational backgrounds, such as IT, archives, libraries or information. 2. There are now specialized agencies that provide training for someone who wants to become an IP professional such as "Special Libraries Association and AlIM The Global Community of Information Professional". 3. Although in Indonesia there is no specific institution of IP service providers, but some institutions have provided forms of IP services, such as Kompas Newspaper Information Center providing information services, National Archives of the Republic of Indonesia and consulting services, Tata Solusi that provide archiving management services. 4. Some libraries in other countries such as Singapore Management University and Nanyang Technology University, started to provide IP services such as consulting facilities and research activities assistance.
\end{abstract}

Key words: Information professionals, library and archive services, information services

*Mahasiswa Program Manajemen Informasi dan Perpustakaan, Sekolah Pascasarjana Universitas Gadjah Mada, Yogyakarta. Mohamad.very13@gmail.com 


\section{Latar Belakang}

Adanya perkembangan mesin pencari informasi seperti google seolah-olah memunculkan harapan kepada masyarakat bahwa sekarang kita dapat dengan mudah menemukan informasi apa saja sesuai harapan kita. $^{1} \mathrm{Di}$ sisi lain muncul permasalahan mengenai kualitas data dan sumber informasi yang kita temukan dari internet. Seperti banyaknya informasi yang kita peroleh dari mesin pencari yang sulit untuk kita ketahui mana informasi yang benar.

Prabha menyampaikan bahwa banyakya informasi yang tersedia seringkali menjadikan seseorang kebingungan untuk memperoleh informasi yang tepat sesuai dengan kebutuhan mereka. Tidak hanya itu, menurut Byron terkadang seorang pencari informasi juga merasa kebingungan untuk menentukan apakah informasi yang mereka peroleh tersebut sudah dapat memenuhi kebutuhan mereka dan apakah informasi tersebut merupakan informasi yang paling tepat. ${ }^{2}$

Pada suatu permasalahan yang sederhana misalnya, saat kita memiliki deadline kerja dan ingin mencari informasi mengenai bagaimana cara cepat melakukan klasifikasi 1000 buku dalam waktu semalam. Mungkin kita akan melakukan pencarian pada google dengan query "cara cepat klasifikasi 1000 buku dalam semalam?". Informasi yang muncul dalam google justru tidak ada yang menjelaskan mengenai jawaban yang tepat, pada jawaban halaman pertama justru yang muncul yaitu 1000 amalan sehari semalam dan kisah candi prambanan dan roro jonggrang mengenai pembuatan 1000 candi dalam waktu semalam. Mungkin kita juga mengganti query yang kita gunakan dengan bahasa Inggris seperti "how to classify 1000 books in a night". Pada pencarian ini informasi yang muncul mengenai 1000 buku untuk anak-anak sebelum TK, cara membaca kata kunci dalam buku, buku dengan judul phantoms on the bookshelves yang sedikit menyinggung klasifikasi penyimpanan buku, dan beberapa informasi lain yang mungkin sedikit menyinggung

\footnotetext{
${ }^{1}$ Putu Laxman Pendit. Perpustakaan Digital: Seri perpustakaan dan Informasi (Jakarta: Sagung Seto, 2007), 142.

${ }^{2}$ Chandra Prabha dkk, "What is enough? Satisficing information needs," Journal of Documentation 63 no. 1 (2007): 74-89.
} 
kegiatan klasfikasi namun belum secara tepat memberikan informasi yang tepat (Percobaan penulis pada google, 06 November 2016). Setelah itu mungkin kita mencoba mencari informasi dari wikipedia atau dari youtube, namun pada kedua media tersebut juga belum menemukan informasi yang kita butuhkan (Percobaan penulis pada wikipedia dan youtube, 06 November 2016).

Hal tersebut menjelaskan bahwa mencari informasi bukan merupakan suatu hal yang mudah, alih-alih kita bukan hanya tidak menemukan informasi, namun bisa saja kita mendapatkan informasi yang keliru. Seperti dalam sebuah perusahaan misalnya, kesalahan informasi sedikit saja tentu akan memberikan dampak yang sangat besar. Yusuf menjelaskan bahwa untuk beberapa informasi penting yang disediakan melalui beberapa sumber, sebenarnya akan lebih baik untuk dikonsultasikan kepada ahli informasi. Hal ini agar para pencari informasi dapat memperoleh informasi yang ideal, sehingga informasi tersebut dapat membantu kegiatan pengambilan keputusan dan meningkatkan produktivitas pekerja. ${ }^{3}$ Edmund menambahkan bahwa seringkali orang yang bekerja dengan banyaknya informasi dari berbagai sumber akan mengalami kesulitan jika hal itu tidak sesuai dengan kemampuannya. ${ }^{4}$ Lalu kepada siapa mereka akan memperoleh informasi yang tepat?

Diantara sumber informasi tersebut yaitu lembaga penyedia informasi atau Information Professional (IP). Widen menjelaskan bahwa adanya IP diperlukan karena adanya perubahan kebutuhan dalam masyarakat informasi dan dalam masyarakat yang berjejaring. Adanya profesional informasi ini dapat membantu mereka untuk menemukan informasi secara tepat. ${ }^{5}$ Contohnya yaitu seorang

\footnotetext{
${ }^{3}$ Tunde Idris Yusuf, "Information Needs, Sources and Information Seeking Behaviour of Women Artisans in Offa Metropolis," Library Philosophy and Practice (e-journal), Paper 1201 (2012), hal. 3. Diakses dari:

(http://digitalcommons.unl.edu/cgi/viewcontent.cgi?article=3134\&context=libphilp rac). Pada 6 November 2016.

${ }^{4}$ Angela Edmunds dan Anne Morris, "The problem of information overload in business organisations: a review of the literature," International Journal of Information Management 20 (2000): 17-28.

${ }^{5}$ Gunilla Widen and Maria Kronqvist-Berg, "The Future Librarian: A Diverse and Complex Professional," Proceedings of the IATUL Conferences (2014), . 2. Diakses
} 
pengusaha yang membutuhkan informasi untuk dapat meningkatkan bisnis yang sudah dia jalani, maka dia memerlukan informasi yang upto-date dari penyedia informasi yang ahli dalam spesialisasinya. ${ }^{6}$ Lalu sebenarnya apa yang dapat dilakukan oleh IP? Artikel ini akan membahas secara lebih lanjut.

\section{Siapakah IP itu?}

Beberapa organisasi yang telah memahami pentingnya pengelolaan informasi yang mereka miliki telah memisahkan kelompok pengelola informasi dalam satu bidang tertentu. Seperti adanya bagian perpustakaan, arsip, atau manajemen informasi. Dengan adanya hal ini penting bagai seorang pengelola informasi menunjukkan profesionalisme mereka sebagai "Information Professional" (IP). IP sendiri menurut Abels dkk sebenarnya bukan sebatas seorang pustakawan, manajer pengetahuan, petugas informasi, pengembang web, broker informasi atau konsultan. IP adalah seseorang yang melakukan pekerjaannya untuk memajukan misi sebuah organisasi. IP melakukan hal tersebut dengan melakukan pengembangan, penyebarluasan, pengelolaan sumber daya informasi, dan layanan informasi. IP juga memanfaatkan teknologi sebagai sarana penting dalam mencapai tujuan. ${ }^{7}$ Mancini berpendapat bahwa IP adalah seseorang yang difokuskan secara khusus pada kegiatan manajemen informasi. Dia tidak hanya orang yang ahli menggunakan IT atau orang yang memiliki salah satu jenis keahlian, namun mereka adalah pengelola informasi yang memiliki sejumlah spesialisasi. ${ }^{8}$

dari:

(https://pdfs.semanticscholar.org/9a3e/c66a9c5f3d7d8f99c2cfc6062c5c60feecc7.p df). Pada 8 November 2016.

${ }^{6}$ Ibid., Tunde Idris Yusuf, hal. 2.

${ }^{7}$ Eileen Abels dkk, "Competencies for Information Professionals of the 21st Century," Special Libraries Association (2003), 1. Diunduh dari: (https://www.sla.org/wp-content/uploads/.../0_LRNCompetencies2003 _revised.pdf). Pada 8 November 2016.

${ }^{8}$ John F Mancini, "The Rise of the Information Professional: A Career Path for the Digital Economy. Aiim,The Global Community of Information Professionals,"(2012), 
Beberapa literatur sebenarnya telah membahas mengenai latar belakang keilmuan seorang IP. Meskipun saat ini mungkin masih banyak perdebatan mengenai latar belakang pendidikan seperti apa yang harus dimiliki seorang IP. Jika kita kaji lebih lanjut IP ini sebenarnya dapat berasal dari berbagai latar belakang pendidikan dan tergantung dari tujuan masing-masing lembaga dimana IP berada, mengingat peran IP merupakan orang yang bekerja untuk memajukan misi sebuah organisasi. IP dapat berasal dari latarbelakang pendidikan ilmu komputer atau bidang IT jika mereka bekerja sebagai pengelolan sistem informasi, atau jika pekerjaan fokus dalam bidang pengelolaan informasi dan sumber-sumbernya, mereka dapat berasal dari bidang manajemen informasi atau bidang perpustakaan. Mason menjelaskan bahwa bidnag IP ini dapat berasal dari tujuh bidang latar belakakng pendidikan. Mereka adalah: Accountant, Archivist, Librarian, Records manager, Information system analyst, Management scientist, Museum curator. ${ }^{9}$

\section{Kompetensi dan Peran IP}

Seorang IP juga harus memiliki beberapa kompetensi yang harus dimiliki. Menurut Abels dkk Professional Competencies yang harus dimiliki oleh IP yaitu: a. Manajemen informasi organisasi, b. Manajemen sumber-sumber informasi, c. Manajemen layanan informasi, d. Implementasi sarana dan teknologi informasi. ${ }^{10}$ Selain itu Abels dkk menyatakan bahwa selain memiliki kompetensi professional IP harus memiliki kompetensi yang berkaitan dengan personal competencies dan core competencies.

a. Personal Competencies, merupakan seperangkat sikap, keterampilan, dan nilai-nilai yang memungkinkan seseorang bekerja secara efektif dan memberikan kontribusi positif bagi organisasi, klien dan profesi mereka. IP juga dituntut untuk fleksibel dalam lingkungan yang selalu berubah.

2. Diakses dari: http://www.aiim.org/pdfdocuments/Rise-of-the-InformationProfessional-White-Paper.pdf. Pada 6 November 2016.

${ }^{9}$ Richard O mason, "What is an Information Professional?," Journal of education for library and information Science 31 no. 2 (1990): 122-138.

${ }^{10}$ Ibid., Eileen Abels dkk, 2. 
b. Core Competencies, merupakan gabungan dari kompetensi professional dan kompetensi personal. Dalam kompetensi ini IP harus dapat mengembangkan dan berbagi pengetahuan. Hal ini dapat dicapai melalui jaringan asosiasi, melakukan berbagi penelitian di konferensi, kontribusi dalam publikasi dan mampu berkolaborasi dalam berbagai hal. ${ }^{11}$

Pendapat lain disampaikan oleh Amin yang menyebutkan bahwa terdapat dua kompetensi dasar yang harsu dimiliki IP sebagai seorang pengelolaan informasi. Kompetensi tersebut yaitu:

a. Information Technology Skill. Pada kompetensi ini IP harus mampu dan berpengetahuan di bidang: Pengembangan sumber informasi digital, Digitalisasi koleksi cetak, Kompetensi untuk mengelola stasiun jaringan, Desain dan pengembangan database, Konversi dari media cetak ke media digital, dan lain sebagainya.

b. Information Retrieval Skill. IP harus menjadi seseorang yang ahli dalam navigasi, browsing dan filtering informasi. Mereka harus mengetahui prosedur mengambil, mengakses dan analisis dokumen digital. Harus mengetahui bagaimana pengoperasian layanan informasi elektronik. Mampu mencari database jaringan melalui sejumlah sumber digital dan situs web. Harus memiliki pengetahuan tentang pelestarian digital dan penyimpananny. Memiliki kemampuan mengoperasikan pesan elektronik dan memiliki keterampilan konektivitas untuk mengakses informasi. ${ }^{12}$

Setelah mengetahui kompetensi yang harus dimiliki seorang IP, lalu apa peran yang dapat dilakukan seorang IP secara detail. Secara lebih lanjut Moran menjelaskan hal-hal yang dapat dilakukan IP seperti:

a. IP dapat menjadi mitra dalam menghasilkan dan mengumpulkan informasi.

11 Ibid., 2-3.

12 Adida Mohd Amin dkk, "Role and function of information professionals in digital libraries," Kekal Abadi 22 no. 2 (2003): 7-13. 
b. IP dapat menjadi rekan penelitian, data mining, atau tim desain, yang dapat menempatkan nilai pada informasi secara akurat dan terorganisasi dengan baik.

c. Seiring banyaknya informasi di era digital, IP harus dapat memperoleh, memahami, mengatur, dan mengevaluasi informasi.

d. IP harus dapat menilai seberapa akurasi informasi yang ada agar dapat meningkatkan akses dan layanan informasi yang dibutuhkan. Selain itu IP juga harus dapat menilai informasi apa yang berguna di masa depan. ${ }^{13}$

\section{Lembaga Penyedia Sertifikat IP}

Sesungguhnya banyak sekali bentuk dari IP yang dapat diterapkan pada masing-masing organisasi. Bentuk-bentuk kegiatan IP mungkin juga dilakukan oleh beberapa orang dengan berbagai macam profesi atau latarbelakang pendidikan. Di beberapa negara seperti Amerika bahkan terdapat lembaga khusus yang menyediakan pendidikan dan pelatihan untuk seseorang yang ingin menjadi IP. Diantaranya yaitu "The Special Libraries Association" (SLA). SLA adalah organisasi nirlaba bagi para profesional informasi. Para anggota pada organisasi ini dapat saling berbagi informasi atau mendapatkan pedoman agar dapat menjadi profesional informasi yang ahli dalam suatu bidang tertentu. Anggota dalam organisasi ini juga membayar biaya keanggotaan setiap tahun. ${ }^{14}$ SLA juga merupakan lembaga IP yang membuka jasa peyediaan dan asistensi penelusuran informasi. Mereka juga menyediakan pelatihan untuk seseorang agar dapat menjadi seseorang IP yang memiliki kompetensi-kompetensi yang dibutuhkan banyak lembaga, dan menyediakan pelatihan subject spesialis yang dapat membantu

13 Barbara B Moran dan Gary Marchionini, Information Professionals 2050: Educating the Next Generation of Information Professionals. Information Professionals 2050: Educational Possibilities and Pathways (Chapel Hill: University of North Carolina, 2012), 12.

${ }^{14}$ About SLA. Diakses dari: (http://www.sla.org/about-sla/). Pada 6 November 2016. 
kebutuhan penelitian. Bahkan mereka menyediakan sertifikat untuk pelatihan yang diberikan. ${ }^{15}$

Adapun materi pelatihan mengenai IP yang disediakan oleh SLA yaitu:

a. Information and Knowledge Services

b. Information and Knowledge Systems and Technology

c. Information and Knowledge Resources

d. Information and Data Retrieval and Analysis

e. Organization of Data, Information, and Knowledge Assets

f. Information Ethics

Lembaga lain penyedia sertifikat IP yaitu "AlIM The Global Community of Information Professional". Pada lembaga ini materi pelatihan yang disediakan mulai dari pelatihan akses dan penggunaan sumber informasi, hingga bagaimana pembentukan arsitektur sistem informasi agar dapat diimplementasikan pada tahap akhir dari tujuan kegiatan IP. Materi yang ditawarkan sebagai berikut: ${ }^{16}$

Tabel 1. Standart Kompetensi IP di AlIM

\begin{tabular}{|l|l|l|}
\hline 1 & Access/ Use & $\begin{array}{l}\text { 1. Enterprise search, 2. Business inteligence, } \\
\text { 3. Master data management, 4. Text } \\
\text { analytic. }\end{array}$ \\
\hline 2 & Capture/ Manage & $\begin{array}{l}\text { 1. Information capture, 2. Business Process } \\
\text { Management, 3. Knowledge management, 4. } \\
\text { Email management, 5. Content } \\
\text { management. }\end{array}$ \\
\hline 3 & $\begin{array}{l}\text { Collaborate/ } \\
\text { Deliver }\end{array}$ & $\begin{array}{l}\text { 1. Colaboration, 2. Social media, 3. } \\
\text { Information workplace, 4. Instant messaging, } \\
\text { 5. Telecomputing support, 6. Web } \\
\text { conferencing. }\end{array}$ \\
\hline 4 & Secure/ Preserve & $\begin{array}{l}\text { 1. Security, 2. Record management, 3. Data } \\
\text { privacy, 4. Digital rights management, 5. } \\
\text { Archiving and E-discovery. }\end{array}$ \\
\hline 5 & Architecture/ & 1. Information Architecture, 2. Technical \\
\hline
\end{tabular}

${ }^{15}$ Research Statement SLA. Diakses dari: (www.sla.org/researchstatement/). Pada 6 November 2016.

${ }^{16}$ Ibid., John F Mancini, 8. 


\begin{tabular}{|l|l|l|}
\hline & Systems & $\begin{array}{l}\text { architecture, 3. Cloud computing, 4. Mobile } \\
\text { applications, 5. Website and Portals. }\end{array}$ \\
\hline 6 & Plan/Implement & $\begin{array}{l}\text { 1. Strategic planning, 2. Building the business } \\
\text { case, 3. Implementation planning, 4. } \\
\text { Requirements definition, 5. Solution design, } \\
\text { 6. Change management. }\end{array}$ \\
\hline
\end{tabular}

\section{Pelaksanaan IP di Perpustakaan}

Seperti yang dijelaskan sebelumnya bahwa IP dapat berasal dari berbagai latar belakang profesi yang berbeda. Yang perlu diingat yaitu apa fokus dari tujuan lembaga dan bagaimana peran dari IP untuk membantu mewujudkan misi tersebut. Seperti IP dari latar belakang TI akan lebih fokus bertanggung jawab untuk pengembangan teknis sebuah sistem informasi dan jika latar belakang IP dari bidang ilmu informasi atau perpustakaan mereka akan berfokus pada konten, organisasi, pengguna, dan pengambilan informasi. ${ }^{17}$

Secara lebih lanjut Amin menjelaskan peran dari IP dalam dunia perpustakaan yang mungkin berbeda dengan layanan yang disediakan oleh perpustakaan di Indonesia. Beberapa hal yang dapat dilakukan seorang IP di perpustakaan yaitu: ${ }^{18}$

a. IP as Consutant

Pada perpustakaan IP harus dapat memandu user dalam pengumpulan informasi, penggunaan sarana penelusuran informasi, pengorganisasian sumber daya informasi, strategi penelitian dan hal lainnya. Layanan ini tentu lebih dari kegiatan pelatihan literasi informasi, mereka harus menyediakan layana secara lebih maju seperti membantu bagaimana mendefinisikan dan menyempurnakan topik penelitian, bagaimana menganalisis informasi yang butuhkan dan bagaimana secara kritis menafsirkan dan mengevaluasi informasi yang dihasilkan dari penelitian.

b. IP as a Member of the Digital Library Design Team

IP juga dapat terlibat dalam desain dan penerapan sistem informasi. Mereka dapat membantu merancang, mengatur, mengembangkan desain dari perpustakaan digital yang dibuat oleh

\footnotetext{
${ }^{17}$ Ibid., Adida Mohd Amin dkk, 7-13.

${ }^{18}$ Ibid., Adida Mohd Amin dkk, 7-13.
} 
ahli IT. Pada hal ini pengetahuan pustakawan mengenai sumber daya informasi dan pengalaman mereka dalam mengarahkan pengguna kepada sumber informasi akan menjadi penting, untuk pengembangan dan pemeliharaan akses informasi dan untuk membuat sistem perpustakaan digital yang memudahkan user.

Pada artikel lain Schonfeld menjelaskan mengenai peran perpustakaan akademik sebagai lembaga profesional untuk lembaga induknya. Menurutnya diantara dukungan perpustakaan sebagai lembaga penyedia informasi yaitu, seperti menyediakan bahan primer secara online yang dapat memudahkan user di perguruan tinggi dalam kegitan penelitian. Layanan ini dapat memanfaatkan sistem komputasi yang menjadikan layanan dapat dilaksanakan secara lebih cepat. Untuk memenuhi hal tersebut Schonfeld menjelaskan beberapa ketrampilan yang harus dimiliki seorang pustakawan yaitu: ${ }^{19}$

a. Mereka memiliki pemahaman tentang bagaimana menggabungkan berbagai sumber data dengan cara yang tepat dalam strategi, perencanaan dan pengembangan secara mandiri ketika data data yang dicari tidak ada. Setiap profesional informasi juga harus memiliki keterampilan dasar pada setiap subjek.

b. Sebuah kemampuan untuk mempertimbangkan kepentingan organisasi entitas yang relevan dalam mengembangkan dan perencanaan strategi, program, dan layanan.

c. IP harus memiliki program yang menarik dan kreatif, seperti mereka dapat menyediakan fasilitas kegiatan-kegiatan yang menarik untuk pelatihan para user di perguruan tinggi.

Kajian lain yang ingin mengetahui peran IP dalam bidang ilmu perpustakaan, kearsipan dan ilmu bidang informasi lainnya,

\footnotetext{
${ }^{19}$ Roger Schonfeld, Information Professionals to Serve Academia. Information Professionals 2050: Educational Possibilities and Pathways (Chapel Hill: University of North Carolina, 2012), 143-144.
} 
menjelaskan bahwa IP untuk masa yang akan datang harus memperhatikan beberapa hal penting. Diantaranya yaitu: ${ }^{20}$

a. IP merupakan seseorang yang dapat menjaga nilai-nilai dan sikap profesional dalam bidangnya. Seorang IP dalam sebuah perpustakaan mislanya, tidak hanya seorang petugas perpustakaan tradisional yang menyediakan layanan kepada user. Namun mereka juga dapat menjadi orang yang mendukung untuk memajukan tujuan dari individu atau organisasi, dengan menjadi lembaga penyedia informasi, pengelola, dan menyediakan akses secara terbuka dan cepat kepada user. Untuk mendukung hal ini mereka juga dapat memanfaatkan teknologi tinggi agar dapat menyediakan variasi-variasi layanan baru dalam menyediakan informasi.

b. Hubungan antar lembaga penyedia informasi yang mengarah pada profesionalisme karir pengelola informasi. Pada lembaga perpustakaan dan kearsipan atau lembaga informasi lainnya mungkin akan didapat pergeseran dari pekerjaan mereka. Sebagai lembaga penyedia informasi mereka harus dapat memenuhi kebutuhan informasi untuk mendukung kegiatan penelitian masyarakat. Mereka juga harus menyediakan pegawai yang fokus dalam bidang penelitian, seperti pustakawan peneliti misalnya.

Adanya syarat-syarat yang diperuntukkan bagi seorang profesional informasi yang berada di perpustakaan menjadikan IP dalam dunia perpustakaan memiliki kriteria kompetensi tersendiri. Hal ini seperti yang disampaikan oleh Widen yang menjelaskan kriteria pustakawan untuk dapat menjadi seorang IP sebagai berikut: ${ }^{21}$

a. Digitalization skills: para pustakawan harus memiliki kompetensi dan kemampuan untuk menggunakan IT.

b. Reading: pustakawan dapat membaca keadaan untuk dapat mengetahui informasi dan media apa yang diperlukan user.

20 Laura Sheble dkk, The Future of Libraries and Archives. Information Professionals 2050: Educational Possibilities and Pathways (Chapel Hill: University of North Carolina, 2012), 85

${ }^{21}$ Ibid., Gunilla Widen and Maria Kronqvist-Berg, 4. 
c. Scholarly communication: mengerti bagaimana kelimuan baru yang diproduksi para peneliti, proses publikasi ilmiah, memahami berbagai macam subjek keilmuan dalam membantu penelusuran informasi, cara penulisan, dan pengembangan penelitian para user.

d. Participatory culture: skills dalam hal penelusuran informasi, berinteraksi dan marketing.

e. Pedagogical skills and supervision: kemampuan untuk menjalin hubungan komunikasi dengan user dan berkolaborasi.

f. Marketing: promosi menggunakan internet dan media baru.

\section{Bentuk Pelaksanaan IP}

Pelaksanaan IP sebenarnya banyak sekali bentuknya. Mereka dapat berupa lembaga penyedia informasi, jasa konsultan penelitian, atau lembaga pelatihan dan pengelolaan sumber-sumber informasi. Di Indonesia meskipun bentuk-bentuk IP belum terlihat secara tegas, tetapi beberapa lembaga telah menyediakan beberapa layanan yang mengarah pada bidang IP. diantaranya seperti yang dilakukan oleh:

a. Pusat Informasi Koran Kompas.

Bagian ini menyediakan layanan informasi yang dapat dimanfaatkan oleh user yang telah mendaftar sebagai anggota. Layanan informasi yang disediakan yaitu sumber informasi dalam bentuk foto, tulisan artikel berita, file grafis dan sebagainya. Sumbersumber informasi tersebut berasal dari hasil koran mereka yang dikumpulkan dari era analog sampai era digital, dan semuanya telah diformulasikan ke dalam bentuk digital.

Sumber informasi yang disediakan oleh koran kompas tersebut merupakan koleksi yang dapat dilanggan secara prabayar atau pasca bayar. Informasi yang dilayankan oleh kompas ini dapat dikomersialkan ulang atau untuk kegiatan nonkomersial. Adapun biaya untuk berlangganan informasi dari Pusat Informasi Koran Kompas sebagai berikut: 
Tabel 2. Daftar Harga Layanan Pusat Informasi Koran Kompas ${ }^{22}$

\begin{tabular}{|c|c|c|c|}
\hline \multicolumn{2}{|c|}{ Pemakaian } & Harga Standar & $\begin{array}{l}\text { Periode/ } \\
\text { Frekuensi }\end{array}$ \\
\hline \multicolumn{4}{|c|}{ Non Komersial } \\
\hline 1. & Koleksi Pribadi & 300.000 & - \\
\hline \multirow[t]{5}{*}{2} & Program Pendidikan & & \\
\hline & Buku & 300.000 & Sekali Cetak \\
\hline & Cover & 1.000 .000 & \\
\hline & Lembaga Masyarakat & 300.000 & Satu Tahun \\
\hline & Lembaga Nirlaba & 300.000 & Satu Tahun \\
\hline \multirow[t]{5}{*}{3.} & Editorial & & \\
\hline & Media Cetak Lokal & 500.000 & Sekali Muat \\
\hline & Media Cetak Asing & 1.000 .000 & Sekali Muat \\
\hline & Media Siar & 1.000 .000 & Satu Tahun \\
\hline & Web & 500.000 & Satu Tahun \\
\hline \multicolumn{4}{|c|}{ Komersial/ Promosi } \\
\hline \multirow[t]{5}{*}{1} & $\mathrm{Ad}$ & & \\
\hline & $\begin{array}{l}\text { Prin Ad Lokal (brosur, iklan } \\
\text { di media cetak }\end{array}$ & 1.000 .000 & Sekali Cetak \\
\hline & Print Ad Asing & 2.000 .000 & Sekali Cetak \\
\hline & $\begin{array}{l}\text { Media Siar Lokal (TV, } \\
\text { Video, Film) }\end{array}$ & 2.000 .000 & Satu Tahun \\
\hline & Media Siar Asing & 4.000 .000 & Satu Tahun \\
\hline
\end{tabular}

b. Arsip Nasional Republik Indonesia

Lembaga lain yang menyediakan layanan profesional yaitu Arsip Nasional Republik Indonesia (ANRI). Sebagai lembaga kearsipan pusat, ANRI menyediakan berbagai macam layanan terkait dengan jasa pengelolaan arsip, konsutasi pengelolaan arsip, preservasi dan

${ }^{22}$ Pusat Informasi Kompas. Diakses dari:

(http://pik.kompas.co.id/product_arsipfoto.cfm). Pada 6 November 2016. 
konservasi arsip, hingga jasa pembuatan pedoman pengelolaan arsip. Layanan yang disediakan oleh ANRI seperti: ${ }^{23}$

1. Jasa penyimpanan arsip dengan harga Rp. 2.250 per boks per bulan.

2. Jasa pembuatan pedoman manual kearsipan dengan tarif $\mathrm{Rp}$. 50.000.000 hingga 110.000 .000 .

3. Jasa pemeliharaan dan perawatan arsip, seperti menghilangkan asam dengan tarif Rp. 7.500, laminasi arsip Rp. 35.000 untuk per lembar arsip ukuran A4.

4. Atau jasa konsultasi tenaga profesional kearsipan dengan tarif yang berbeda sesuai kebutuhan lembaga. Dan berbagai layanan lainnya.

\section{c. Tata Solusi}

Lembaga lain yang memberikan jasa profesional yaitu jasa konsultan "Tata Solusi". Lembaga ini milik perseorangan yang menawarkan berbagai macam produk terkait dengan kegiatan pengelolaan arsip dan informasi. Adapun layanan yang disediakan bermacam-macam. Diantara layanan tersebut seperti jasa pengelolaan dokumen, jasa pengelolaan informasi, jasa penyediaan sistem informasi berbagai bidang yang dibutuhkan oleh berbagai perusahaan. Seperti sistem informasi perpustakaan, sistem informasi pengelolaan arsip dan lain sebagainya. Lembaga ini juga mengadakan pelatihan kegiatan pengelolaan arsip dan informasi bagi orang yang membutuhkan. ${ }^{24}$

\section{Pelaksanaan IP di Perpustakaan}

Beberapa di negara lain sebenarnya telah melaksanakan beberapa kegiatan IP seperti layanan asistensi untuk kegiatan penelitian dan bantuan penyediaan literatur yang yang diusulkan pustakawan kepada user. Diantara perpustakaan tersebut seperti:

${ }^{23}$ Peraturan Pemerintah Republik Indonesia Nomor 42 Tahun 2005 tentang Jenis dan Tarif Atas Jenis Penerimaan Negara Bukan Pajak yang Berlaku Pada Arsip Nasional Republik Indonesia.

${ }^{24}$ Tata Solusi. Diakses dari: (http://tatasolusi.co.id/jasa-tata-solusi.html). Pada 6 November 2016. 
Perpustakaan Singapore Management University (SMU). Pada perpustakaan ini menyediakan fasilitas Research Consultation untuk para user. Fasilitas konsultasi yang disediakan sebagai berikut: ${ }^{25}$

a. Meet your librarian, fasilitas yang menyediakan subjek spesialis yang membantu para peneliti untuk memenuhi kebutuhan informasi dalam penelitiannya. Pada layanan ini user dapat membuat janji terlebih dahulu melalui website perpustakaan jika mereka ingin bertemu dengan pustakawan yang dituju.

b. Research consultation dan research guide, layanan yang memberikan informasi mengenai berbagai literatur dan sumber-sumber jurnal untuk disarankan kepada user yang mungkin diperlukan.

c. Citation and style guide, merupakan layanan untuk membuat citasi dari beberapa model yang dilengkapi dengan tutorial video.

Perpustakaan lain yang melaksanakan bentuk layanan IP yaitu perpustakaan Nanyang Technology University (NTU). Perpustakaan NTU menyediakan subjek spesialis yang ahli dalam masing-masing bidang penelitian sebanyak 35 pustakawan. Layanan subject librarian pada perpustakaan NTU. Perpustakaan lainnya yaitu perpustakaan Harvard University. Perpustakaan ini menyediakan fasilitas reserch guide. Fasilitas ini akan membantu para user untuk lebih mudah memahami bagaimana cara melakukan penelitian yang baik meskipun jenis penelitian tersebut mungkin belum pernah mereka lakukan. Fasilitas reserch guide ini memberikan informasi seputar riset mulai dari proses menentukan tema penelitian, alur penelitian, hingga pengolahan data penelitian. Pada fitur research guide dilengkapi link video pada youtube yang membantu mempermudah user memahami materi yang disampaikan. Mereka juga menyediakan beberapa link

${ }^{25}$ Moh Very Setiawan, “Inovasi Layanan Refrensi pada Perpustakaan Peguruan Tinggi Sebagai Penunjang Kegiatan Penelitian Civitas Akademika," Prosiding Seminar SLiMS Commeet West Java 2016. Kreativitas Pustakawan pada Era digital dalam Menyediakan Sumber Informasi bagi Generasi Digital Native (Bandung: Unpad Press, 2016), 248.. 
yang merujuk pada tools yang dapat digunakan sebagai sarana pengolahan atau pengukuran data terkait suatu tema penelitian. ${ }^{26}$

\section{Kesimpulan}

Berdasarkan pembahasan artikel ini dapat disimpulkan bahwa IP sebenarnya dapat berasal dari berbagai bidang profesi terkait dengan kegiatan dalam bidang pelayanan informasi. Yang membedakan yaitu fokus bidang kerja IP yang berfungsi untuk membantu mewujudkan misi lembaga induknya. Seperti jika bidang kerja pada Sistem Informasi, IP dapat berasal dari profesi IT, jika dalam kegiatan pengelolaan dokumen IP dapat berasal dari profesi arsip dan untuk pengelolaan perpustakaan dan informasi IP dapat berasal dari profesi pustakawan. Adapun layanan yang disediakan oleh IP dapat berupa jasa informasi, asistensi, konsultasi atau pengelolaan arsip. Di Amerika IP sudah mulai berkembang dan bahkan telah terdapat lembaga khusus untuk IP dan pelatihan bagi seseorang yang ingin menjadi IP. Lembaga tersebut yaitu "Special Libraries Association dan AlIM The Global Community of Information Professional". Pada beberapa perpustakaan di negara lain seperti pada Singapore Management University dan Nanyang Technology University, mulai menyediakan layanan berbasis IP dalam bentuk konsultasi atau asistensi kegiatan penelitian. Pada kedua perpustakaan tersebut menyediakan staff yang merupakan spesialis subjek yang dapat ditemui user dengan membuat janji terlebih dahulu. Selain itu perpustakaan juga memberikan rujukan sumber informasi yang dapat digunakan oleh user mengenai tema-tema penelitian yang dilakukan.

\section{Daftar Pustaka}

Abels, Eileen dkk. "Competencies for Information Professionals of the 21st Century." Special Libraries Association (2003). Diunduh dari: $\quad$ (https://www.sla.org/wpcontent/uploads/.../0 LRNCompetencies2003 revised.pdf). Pada 8 November 2016. 
Amin, Adida Mohd dkk. "ROLE AND FUNCTION OF INFORMATION PROFESSIONALS IN DIGITAL LIBRARIES." Kekal Abadi 22 no. 2 (2003): 7-13.

Edmunds, Angela dan Anne Morris. "The problem of information overload in business organisations: a review of the literature." International Journal of Information Management 20 (2000): 17-28.

Mancini, John F. "The Rise of the Information Professional: A Career Path for the Digital Economy. Aiim, The Global Community of Information Professionals." (2012). Diakses dari: (http://www.aiim.org/pdfdocuments/Rise-of-the-InformationProfessional-White-Paper.pdf). Pada 6 November 2016.

Mason, Richard O. What is an Information Professional?. Journal of education for library and information Science 31 no. 2 (1990): 122-138.

Moran, Barbara B dan Gary Marchionini. Information Professionals 2050: Educating the Next Generation of Information Professionals. Information Professionals 2050: Educational Possibilities and Pathways. (Chapel Hill: University of North Carolina, 2012).

Pendit, Putu Laxman. Perpustakaan Digital: Seri perpustakaan dan Informasi. (Jakarta: Sagung Seto, 2007).

Peraturan Pemerintah Republik Indonesia Nomor 42 Tahun 2005 tentang Jenis dan Tarif Atas Jenis Penerimaan Negara Bukan Pajak yang Berlaku Pada Arsip Nasional Republik Indonesia.

Prabha, Chandra dkk. "What is enough? Satisficing information needs." Journal of Documentation 63 no. 1 (2007).

Schonfeld, Roger. Information Professionals to Serve Academia. Information Professionals 2050: Educational Possibilities and Pathways. (Chapel Hill: University of North Carolina, 2012).

Setiawan, Moh Very. "Inovasi Layanan Refrensi pada Perpustakaan Peguruan Tinggi Sebagai Penunjang Kegiatan Penelitian Civitas Akademika." Prosiding Seminar SLiMS Commeet West Java 2016. Kreativitas Pustakawan pada Era digital dalam Menyediakan Sumber Informasi bagi Generasi Digital Native. (Bandung: Unpad Press, 2016). 
Sheble, laura dkk. The Future of Libraries and Archives. Information Professionals 2050: Educational Possibilities and Pathways. (Chapel Hill: University of North Carolina, 2012).

Gunilla Widen and Maria Kronqvist-Berg, "The Future Librarian: A Diverse and Complex Professional," Proceedings of the IATUL Conferences (2014), hal. 2. Diakses dari: (https://pdfs.semanticscholar.org/9a3e/c66a9c5f3d7d8f99c2cfc 6062c5c60feecc7.pdf). Pada 8 November 2016.

Widen, Gunilla and Maria Kronqvist-Berg. "The Future Librarian: A Diverse and Complex Professional." Proceedings of the IATUL Conferences. $2014 . \quad$ Diakses dari: (https://pdfs.semanticscholar.org/9a3e/c66a9c5f3d7d8f99c2cfc 6062c5c60feecc7.pdf). Pada 8 November 2016.

Yusuf, Tunde Idris. "Information Needs, Sources and Information Seeking Behaviour of Women Artisans in Offa Metropolis." Library Philosophy and Practice (e-journal). Paper 1201. (2012). Diakses

dari:

(http://digitalcommons.unl.edu/cgi/viewcontent.cgi?article=31 34\&context=libphilprac). Pada 6 November 2016.

\section{Website:}

About SLA. Diakses dari: (http://www.sla.org/about-sla/). Pada 6 November 2016.

Research Statement SLA. Diakses dari:

(www.sla.org/researchstatement/). Pada 6 November 2016.

Pusat Informasi Kompas. Diakses dari:

(http://pik.kompas.co.id/product arsipfoto.cfm). $\quad$ Pada 6 November 2016.

Tata Solusi. Diakses dari: (http://tatasolusi.co.id/iasa-tatasolusi.html). Pada 6 November 2016. 